\title{
Stone Image Classification Based on Overlapped 5-bit T-Patterns Occurrence on 5-by-5 Sub Images
}

\author{
Palnati Vijay Kumar, Pullela S V V S R Kumar, Nakkella Madhuri, M Uma Devi \\ Department of Computer Science \& Engineering, Aditya College of Engineering, Surampalem, Andhra Pradesh, India
}

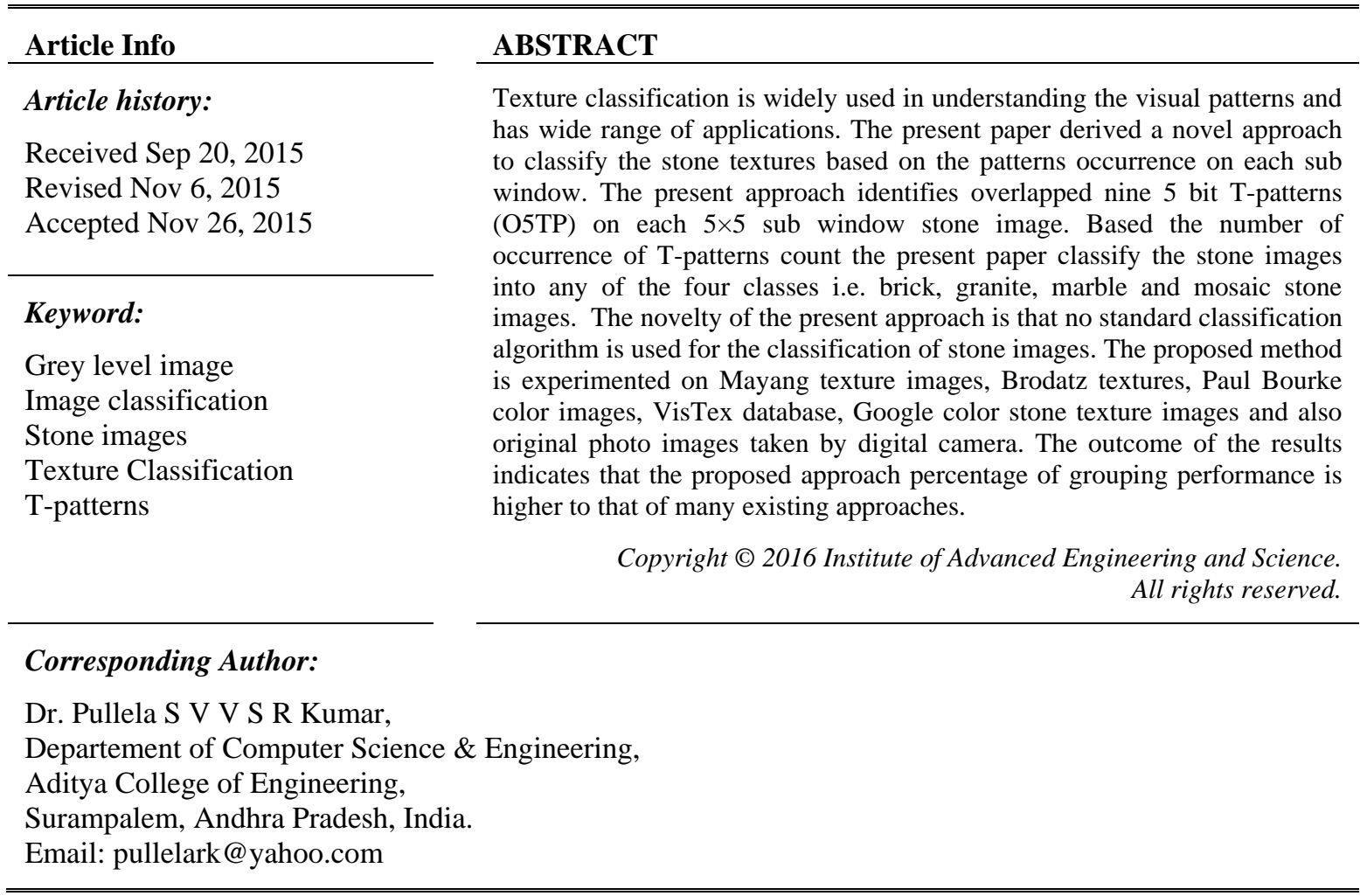

\section{INTRODUCTION}

TEXTURE analysis and categorization are important for the interpretation and understanding of real-world visual patterns. Texture classification has a wide variety of prospective applications [1] such as regions classification in satellite images [2], defects detection in industrial surface inspection [3], and classification of pulmonary disease [4], diagnosis of leukemic cells in medical image [5] and breast cancer classification [6]. Texture analysis and classification is majorly achieved in one of the two ways, i.e. statistical approach and structural method. Statistical approach mainly concentrates on the stochastic things of the spatial distribution of gray levels in an image. Generally for finding the characteristics, co-occurrence matrix is frequent. From the co-occurrence matrix set of textural features extracted and these features are widely used to extract textural information from digital images [7],[8]. In structural approach, texture is considered as a repetition of some primitives. For texture classification and characterization, these methods have been applied by several authors and achieved success to a certain degree [9].

Characterization and classification of textures is an important step in the study of patterns on texture images. The textures are characterized and classified recently by various pattern approach methods: edge direction movements [10], long linear patterns [11],[12] and preprocessed images [13]. Marble texture description [14], avoiding Complex Patterns [15], Texture images are also described and classified by using various wavelet transforms techniques: one based on statistical parameters [16] and another one based on primitive patterns [17].

Sasi Kiran et.al [18] has proposed a method called Wavelet based Histogram on texton patterns (WHPT) and grouped the stone textures into four categories. The WHTP method got average \% of grouping 
as 94.56. Dr. U Ravi Babu et.al [19] has proposed a method for stone textures classification into four groups. In this method also used patterns approach on grey-to-grey level preprocessed images. This method also achieved $97.15 \%$ as group classification, but this method is applied only for grouping stone textures into four groups. Suma Latha et.al. [20] has proposed a method called LBP-High-Symmetry (LBP-HS) for recognition of stone textures. This approach is also patterned approach for stone texture recognition. The LBP-HS method got $92 \%$ of recognition only. Sujatha B et al [21] proposed a method called Texton and Texture Orientation Co-occurrence Matrix (T\&TO-CM) for the classification of textures. The proposed method achieved only $93 \%$ of classification rate.

In most approaches, which have been offered so far, researchers have tried to analyze and describe texture based on overlapped alphabet patterns for stone image classification. The proposed method put forward the pattern approach for grouping the stone textures into four classes. The high accuracy in texture classification in the results shows the quality of offered approach. The present paper proposes an approach for stone textures classification based on occurrences of overlapped T-patterns on each $5 \times 5$ sub-images.

The reminder of this paper is organized as follows: Section two describes to the identification of Overlapped 5-bit T-Patterns (O5TP) on the grey level image. Section three is related to deriving an algorithm for grouping the stone texture and analyses the results and finally, the conclusion included.

\section{PROPOSED METHOD}

\subsection{Identification of Overlapped 5 -bit T-Patterns on Each $5 \times 5$ sub-stone image}

The proposed method O5TP consists of 4 steps. In step 1, convert the each stone texture color into the grey level image by using 7-bit binary code quantization method. Identify the 5 -bit T-patterns in each $5 \times 5$ window of the stone texture image in step 2. In step 3, count the occurrences of T-patterns. Finally, based on the number of T-patterns derive a new algorithm for classification. The block diagram of the entire procedure is shown in Figure 1.

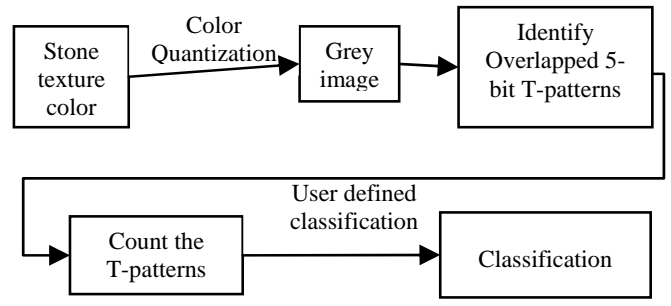

Figure 1. Block diagram of the proposed stone image classification

Step 1: Color to Grey Scale conversion

The Color image is nothing but a color channels. Most digital images are comprised of three separate color channels: a red channel, a green channel, and a blue channel. Grey scale means many shades (grey) from black to white. Generally, 7 ways are available to convert the color image into gray scale image i.e. averaging method, luma method, and De-saturation method, Custom \#of gray shades method, horizontal error-diffusion dithering method, Single color channel and Single color channel method. In this paper utilized Custom \# of gray shades method.

Custom \# of gray shades method: this allows the user to specify how many shades of gray the resulting image will use. This value can be between 2 and 256 is accepted. If it is 2, the resultant image contains 2 shades i.e. black-and-white image, while 256 gives an image consists of 256 shades. The proposed method uses 8-bit color channels. So, maximum shades are only 256. In this paper uses 128 shades.

Any grayscale conversion algorithm is a three-step process:

1. Catch the green, red and blue values of a pixel

2. Convert those three values into a single gray value

3. Replace the three values with the new gray value

Elaborated algorithm for Grey Scale conversion

Step 1: Exchange threshold value $=255 /($ Number Of Shades-1)

Step 2: mean value $=($ Red + Green + Blue $) / 3$

Step 3: Gray = Integer (mean value / exchange threshold value) * exchange threshold value

Step 2: identification of 5-bit T-patterns each $5 \times 5$ grey-level stone sub image

The $5 \times 5$ sub image values are represented as $\mathrm{P}_{1}, \mathrm{P}_{2}, \ldots \mathrm{P}_{9}, \mathrm{P}_{10}, \mathrm{P}_{11}, \ldots \mathrm{P}_{24}, \mathrm{P}_{25}$. The pixel position of the each $5 \times 5$ sub window was shown in Figure 2 . 


\begin{tabular}{|c|c|c|c|c|}
\hline 1 & 2 & 3 & 4 & 5 \\
\hline 6 & 7 & 8 & 9 & 10 \\
\hline 11 & 12 & 13 & 14 & 15 \\
\hline 16 & 17 & 18 & 19 & 20 \\
\hline 21 & 22 & 23 & 24 & 25 \\
\hline
\end{tabular}

Figure 2. Pixel positions in $5 \times 5$ grey level facial sub image

In the proposed method consider the all possible T-pattern formed using 5-bits. The first T-pattern formed using 5 pixel $\mathrm{P}_{1}, \mathrm{P}_{2}, \mathrm{P}_{3}, \mathrm{P}_{7}$, and $\mathrm{P}_{12}$ and the second T-pattern formed using 5 pixel $\mathrm{P}_{2}, \mathrm{P}_{3}, \mathrm{P}_{4}, \mathrm{P}_{8}$, and $\mathrm{P}_{13}$ and so on. From first row 3 T-patterns are formed. From the Second row, another 3 T-patterns are formed. From the $3^{\text {rd }}$ row another set of 3 patterns formed. Totally, nine overlapped 5-bit T-patterns are possible in each $5 \times 5$ sub window. Figure 3 shows the possible overlapped T-patterns on each $5 \times 5$ window.
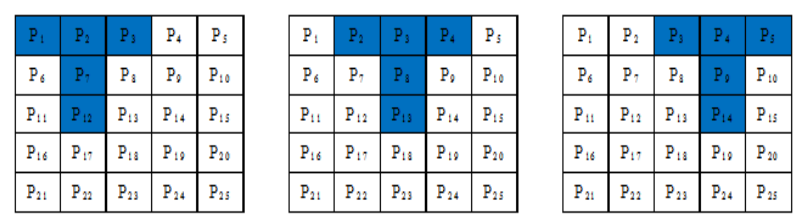

\begin{tabular}{|c|c|c|c|c|}
\hline $\mathrm{P}_{1}$ & $\mathrm{P}_{2}$ & $\mathrm{P}_{1}$ & $\mathrm{P}_{4}$ & $\mathrm{P}_{5}$ \\
\hline $\mathrm{P}_{6}$ & $\mathrm{P}_{7}$ & $\mathrm{P}_{1}$ & $\mathrm{P}_{8}$ & $\mathrm{P}_{10}$ \\
\hline $\mathrm{P}_{14}$ & $\mathrm{P}_{12}$ & $\mathrm{P}_{13}$ & $\mathrm{P}_{14}$ & $\mathrm{P}_{13}$ \\
\hline $\mathrm{P}_{16}$ & $\mathrm{P}_{12}$ & $\mathrm{P}_{18}$ & $\mathrm{P}_{10}$ & $\mathrm{P}_{20}$ \\
\hline $\mathrm{P}_{24}$ & $\mathrm{P}_{22}$ & $\mathrm{P}_{23}$ & $\mathrm{P}_{24}$ & $\mathrm{P}_{25}$ \\
\hline
\end{tabular}

\begin{tabular}{|l|l|l|l|l|}
\hline $\mathrm{P}_{1}$ & $\mathrm{P}_{2}$ & $\mathrm{P}_{3}$ & $\mathrm{P}_{4}$ & $\mathrm{P}_{5}$ \\
\hline $\mathrm{P}_{6}$ & $\mathrm{P}_{1}$ & $\mathrm{P}_{1}$ & $\mathrm{P}_{8}$ & $\mathrm{P}_{10}$ \\
\hline $\mathrm{P}_{14}$ & $\mathrm{P}_{12}$ & $\mathrm{P}_{13}$ & $\mathrm{P}_{14}$ & $\mathrm{P}_{15}$ \\
\hline $\mathrm{P}_{16}$ & $\mathrm{P}_{17}$ & $\mathrm{P}_{18}$ & $\mathrm{P}_{18}$ & $\mathrm{P}_{20}$ \\
\hline $\mathrm{P}_{21}$ & $\mathrm{P}_{22}$ & $\mathrm{P}_{23}$ & $\mathrm{P}_{24}$ & $\mathrm{P}_{25}$ \\
\hline
\end{tabular}

\begin{tabular}{|l|l|l|l|l|}
\hline $\mathrm{P}_{1}$ & $\mathrm{P}_{2}$ & $\mathrm{P}_{1}$ & $\mathrm{P}_{4}$ & $\mathrm{P}_{5}$ \\
\hline $\mathrm{P}_{6}$ & $\mathrm{P}_{7}$ & $\mathrm{P}_{4}$ & $\mathrm{P}_{8}$ & $\mathrm{P}_{10}$ \\
\hline $\mathrm{P}_{14}$ & $\mathrm{P}_{12}$ & $\mathrm{P}_{13}$ & $\mathrm{P}_{14}$ & $\mathrm{P}_{15}$ \\
\hline $\mathrm{P}_{16}$ & $\mathrm{P}_{17}$ & $\mathrm{P}_{18}$ & $\mathrm{P}_{10}$ & $\mathrm{P}_{20}$ \\
\hline $\mathrm{P}_{24}$ & $\mathrm{P}_{22}$ & $\mathrm{P}_{23}$ & $\mathrm{P}_{24}$ & $\mathrm{P}_{25}$ \\
\hline
\end{tabular}

\begin{tabular}{|l|l|l|l|l|}
\hline $\mathrm{P}_{1}$ & $\mathrm{P}_{2}$ & $\mathrm{P}_{3}$ & $\mathrm{P}_{4}$ & $\mathrm{P}_{5}$ \\
\hline $\mathrm{P}_{6}$ & $\mathrm{P}_{7}$ & $\mathrm{P}_{4}$ & $\mathrm{P}_{0}$ & $\mathrm{P}_{10}$ \\
\hline $\mathrm{P}_{11}$ & $\mathrm{P}_{12}$ & $\mathrm{P}_{13}$ & $\mathrm{P}_{14}$ & $\mathrm{P}_{15}$ \\
\hline $\mathrm{P}_{16}$ & $\mathrm{P}_{12}$ & $\mathrm{P}_{18}$ & $\mathrm{P}_{10}$ & $\mathrm{P}_{20}$ \\
\hline $\mathrm{P}_{21}$ & $\mathrm{P}_{21}$ & $\mathrm{P}_{23}$ & $\mathrm{P}_{24}$ & $\mathrm{P}_{25}$ \\
\hline
\end{tabular}

\begin{tabular}{|l|l|l|l|l|}
\hline $\mathrm{P}_{1}$ & $\mathrm{P}_{2}$ & $\mathrm{P}_{1}$ & $\mathrm{P}_{4}$ & $\mathrm{P}_{5}$ \\
\hline $\mathrm{P}_{6}$ & $\mathrm{P}_{7}$ & $\mathrm{P}_{1}$ & $\mathrm{P}_{8}$ & $\mathrm{P}_{10}$ \\
\hline $\mathrm{P}_{14}$ & $\mathrm{P}_{12}$ & $\mathrm{P}_{13}$ & $\mathrm{P}_{14}$ & $\mathrm{P}_{15}$ \\
\hline $\mathrm{P}_{16}$ & $\mathrm{P}_{17}$ & $\mathrm{P}_{18}$ & $\mathrm{P}_{18}$ & $\mathrm{P}_{20}$ \\
\hline $\mathrm{P}_{24}$ & $\mathrm{P}_{22}$ & $\mathrm{P}_{23}$ & $\mathrm{P}_{24}$ & $\mathrm{P}_{25}$ \\
\hline
\end{tabular}

\begin{tabular}{|l|l|l|l|l|}
\hline $\mathrm{P}_{1}$ & $\mathrm{P}_{2}$ & $\mathrm{P}_{3}$ & $\mathrm{P}_{4}$ & $\mathrm{P}_{3}$ \\
\hline $\mathrm{P}_{6}$ & $\mathrm{P}_{2}$ & $\mathrm{P}_{4}$ & $\mathrm{P}_{8}$ & $\mathrm{P}_{10}$ \\
\hline $\mathrm{P}_{14}$ & $\mathrm{P}_{12}$ & $\mathrm{P}_{13}$ & $\mathrm{P}_{14}$ & $\mathrm{P}_{15}$ \\
\hline $\mathrm{P}_{16}$ & $\mathrm{P}_{12}$ & $\mathrm{P}_{13}$ & $\mathrm{P}_{18}$ & $\mathrm{P}_{20}$ \\
\hline $\mathrm{P}_{24}$ & $\mathrm{P}_{22}$ & $\mathrm{P}_{23}$ & $\mathrm{P}_{24}$ & $\mathrm{P}_{25}$ \\
\hline
\end{tabular}

Figure 3. Overlapped 5-bit T-patterns on each $5 \times 5$ window

Step 3: Count the T-patterns

Count the frequency occurrence of the considered patterns in each $5 \times 5$ sub window on the stone texture adds these values to the feature vector.

Step 4: Classification of stone texture images

Based on frequency occurrences of overlapped 5-bit T-pattern in each $5 \times 5$ sub window on the stone texture image is classified as one of the four categories i.e. brick, Marble, Mosaic and Granite.

\section{RESULTS AND DISCUSSION}

To find the effectiveness of the proposed approach (O5TP) carried out the experiments on mixed stone textures Dataset which consists of various brick, granite, marble, and mosaic stone textures collected from Mayang, Google, CuRet VisTex, and Paul Bourke data-base and also from floor images taken by camera with the resolution of $256 \times 256$. The images used in this experiment is 1880 i.e. 480 images from Mayang database, 410 images from Paul Bourke database, 160 images from VisTex database, 130 images from CuRet database 300 images from Google database and 400 images from scanned photo graphs. Figure 4 shows the some of the stone textures used in this paper to evaluate the efficiency of the proposed approach. Some of the frequency of occurrence of overlapped 5-bit T-pattern (O5TP) of marble, mosaic, granite, and brick texture dataset images are listed-out in table 1 to 4 respectively. From Tables 1 to 5 designs a classification graph of five categories of stone images is shown in Figure 5. 


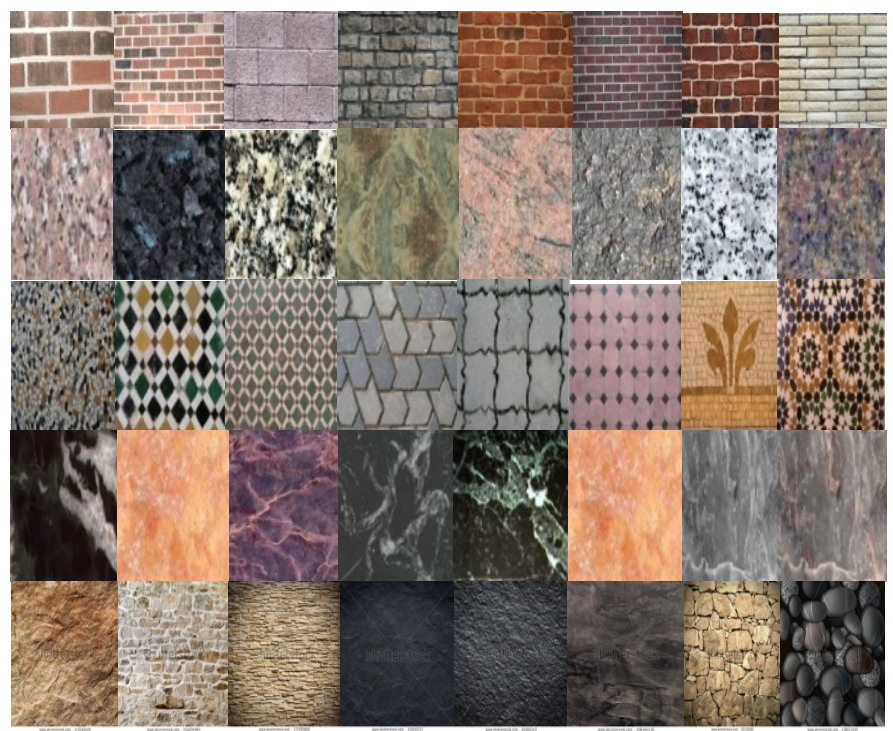

Figure 4. some of the stone images used in this method with resolution of $256 \times 256$

Table 1. Overlapped 5-bit T-patterns occurrences of Brick textures

\begin{tabular}{lcccccccccc}
\hline Image Name & Pattern1 & Pattern2 & Pattern3 & Pattern4 & Pattern5 & Pattern6 & Pattern7 & Pattern8 & Pattern9 & Total \\
\hline Brick.0001 & 129 & 84 & 78 & 126 & 140 & 96 & 124 & 99 & 125 & 1001 \\
Brick.0002 & 122 & 138 & 136 & 122 & 133 & 129 & 137 & 135 & 128 & 1180 \\
Brick.0003 & 132 & 125 & 126 & 129 & 135 & 129 & 139 & 134 & 132 \\
Brick.0004 & 133 & 147 & 131 & 136 & 155 & 128 & 137 & 141 & 124 \\
Brick.0005 & 139 & 139 & 135 & 135 & 151 & 139 & 136 & 145 & 142 & 1232 \\
Brick.0006 & 140 & 140 & 142 & 139 & 147 & 138 & 143 & 151 & 139 \\
Brick.0007 & 146 & 157 & 134 & 150 & 153 & 149 & 162 & 158 & 155 \\
Brick.0008 & 170 & 175 & 156 & 168 & 168 & 158 & 168 & 168 & 158 \\
Brick.0009 & 165 & 174 & 153 & 178 & 179 & 151 & 166 & 181 & 166 \\
Brick.0010 & 168 & 171 & 158 & 168 & 172 & 161 & 176 & 181 & 164 \\
Brick.0011 & 162 & 169 & 163 & 176 & 166 & 181 & 176 & 170 & 176 \\
Brick.0012 & 212 & 220 & 185 & 199 & 205 & 180 & 196 & 224 & 199 \\
Brick.0013 & 192 & 205 & 185 & 203 & 218 & 199 & 210 & 221 & 201 \\
Brick.0014 & 232 & 249 & 245 & 202 & 218 & 217 & 201 & 218 & 216 \\
Brick.0015 & 221 & 222 & 219 & 235 & 238 & 214 & 233 & 239 & 216 \\
Brick.0016 & 251 & 256 & 239 & 259 & 277 & 253 & 279 & 299 & 263 \\
Brick.0017 & 295 & 288 & 302 & 286 & 289 & 303 & 264 & 275 & 283 \\
Brick.0018 & 429 & 433 & 416 & 424 & 431 & 402 & 418 & 421 & 2380 \\
Brick.0019 & 447 & 452 & 453 & 440 & 444 & 439 & 425 & 434 & 425 \\
Brick.0020 & 616 & 631 & 438 & 584 & 412 & 468 & 608 & 613 & 378 \\
\hline
\end{tabular}

Table 2. Overlapped 5-bit T-patterns occurrences of Granite textures

\begin{tabular}{|c|c|c|c|c|c|c|c|c|c|c|}
\hline Image Name & Pattern1 & Pattern2 & Pattern3 & Pattern4 & Pattern5 & Pattern6 & Pattern7 & Pattern8 & Pattern9 & Total \\
\hline blue_granite & 2 & 3 & 1 & 2 & 1 & 5 & 4 & 0 & 0 & 18 \\
\hline blue_pearl & 2 & 1 & 2 & 1 & 2 & 3 & 1 & 4 & 4 & 20 \\
\hline blue_topaz & 0 & 4 & 0 & 0 & 0 & 4 & 3 & 0 & 4 & 15 \\
\hline brick_erosion & 2 & 0 & 4 & 0 & 0 & 0 & 0 & 0 & 0 & 6 \\
\hline canyon_black & 0 & 1 & 4 & 2 & 0 & 1 & 0 & 0 & 1 & 9 \\
\hline dapple_green & 1 & 1 & 3 & 2 & 0 & 2 & 2 & 3 & 0 & 14 \\
\hline ebony_oxide & 0 & 1 & 2 & 1 & 2 & 4 & 0 & 1 & 0 & 11 \\
\hline giallo_granite & 1 & 4 & 0 & 0 & 0 & 0 & 2 & 0 & 1 & 8 \\
\hline gosford_stone & 0 & 0 & 2 & 3 & 4 & 2 & 1 & 1 & 0 & 13 \\
\hline greenstone & 0 & 1 & 4 & 0 & 2 & 3 & 2 & 0 & 0 & 12 \\
\hline interlude_haze & 4 & 2 & 0 & 3 & 2 & 1 & 0 & 0 & 0 & 12 \\
\hline kalahari & 0 & 4 & 2 & 2 & 1 & 1 & 3 & 1 & 1 & 15 \\
\hline mesa_twilight & 4 & 1 & 1 & 0 & 1 & 2 & 3 & 2 & 0 & 14 \\
\hline mesa_verte & 0 & 1 & 4 & 3 & 1 & 1 & 1 & 0 & 0 & 11 \\
\hline monza & 4 & 0 & 0 & 3 & 2 & 1 & 0 & 1 & 0 & 11 \\
\hline pietro_nero & 1 & 2 & 2 & 1 & 4 & 1 & 3 & 0 & 0 & 14 \\
\hline russet_granite & 0 & 4 & 1 & 1 & 0 & 0 & 1 & 0 & 0 & 7 \\
\hline granite10 & 0 & 2 & 0 & 0 & 0 & 4 & 3 & 1 & 0 & 10 \\
\hline granite13 & 4 & 3 & 2 & 0 & 1 & 1 & 0 & 1 & 0 & 12 \\
\hline granite20 & 1 & 0 & 0 & 1 & 1 & 4 & 2 & 3 & 0 & 12 \\
\hline
\end{tabular}


Table 3. Overlapped 5-bit T-patterns occurrences in Horizontal Direction of Marble textures

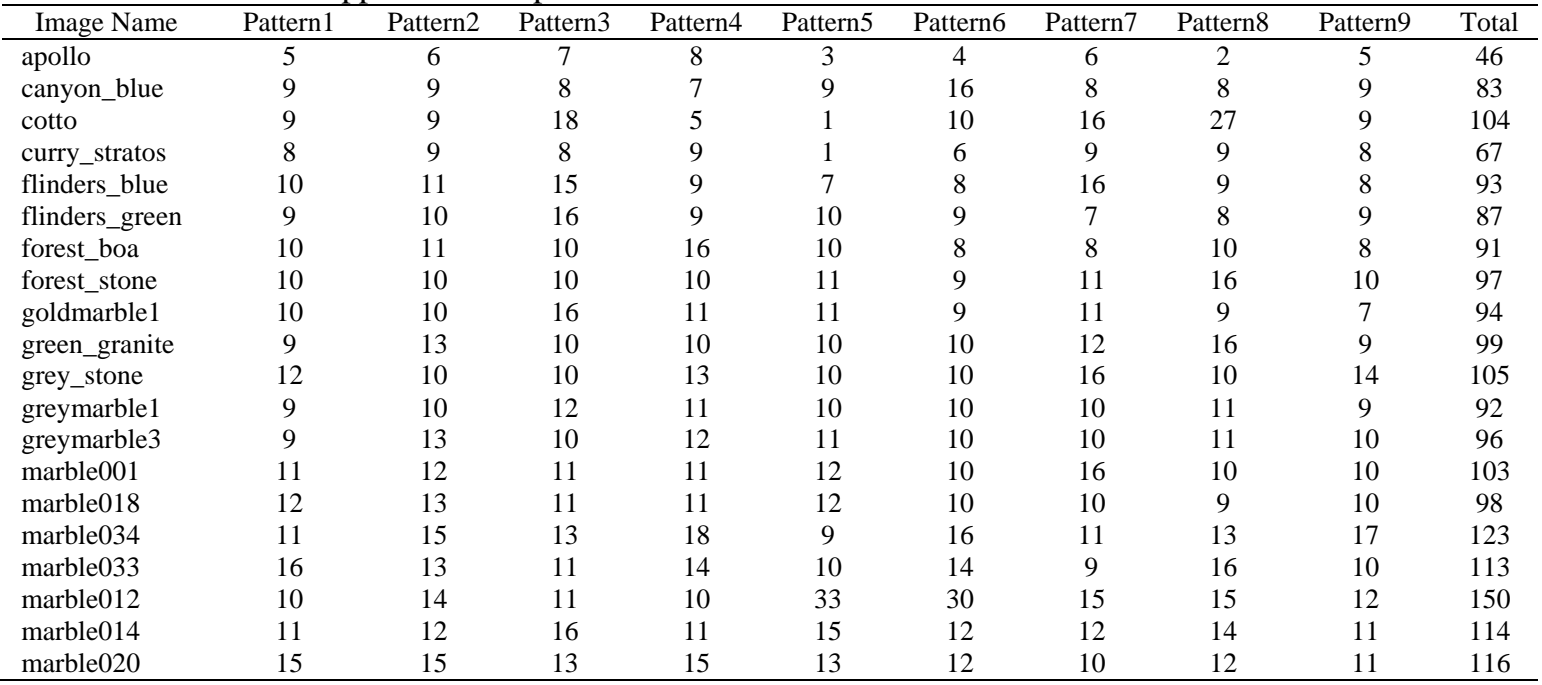

Table 4. Overlapped 5-bit T-patterns occurrences in Horizental Direction of Mosaic textures

\begin{tabular}{|c|c|c|c|c|c|c|c|c|c|c|}
\hline Image Name & $\begin{array}{c}\text { Pattern } \\
1 \\
\end{array}$ & $\begin{array}{c}\text { Pattern } \\
2 \\
\end{array}$ & $\begin{array}{c}\text { Pattern } \\
3 \\
\end{array}$ & $\begin{array}{c}\text { Pattern } \\
4\end{array}$ & $\begin{array}{c}\text { Pattern } \\
5 \\
\end{array}$ & $\begin{array}{c}\text { Pattern } \\
6\end{array}$ & $\begin{array}{c}\text { Pattern } \\
7 \\
\end{array}$ & $\begin{array}{c}\text { Pattern } \\
8 \\
\end{array}$ & $\begin{array}{c}\text { Pattern } \\
9 \\
\end{array}$ & Total \\
\hline concrete_bricks_170756 & 52 & 55 & 52 & 157 & 56 & 107 & 75 & 56 & 56 & 666 \\
\hline concrete_bricks_170757 & 58 & 56 & 52 & 155 & 57 & 106 & 73 & 56 & 55 & 668 \\
\hline concrete_bricks_170776 & 55 & 58 & 53 & 154 & 58 & 106 & 76 & 54 & 56 & 670 \\
\hline crazy_paving_50̄91370 & 54 & 57 & 56 & 154 & 60 & 105 & 77 & 58 & 54 & 675 \\
\hline crazy_paving_5091376 & 58 & 56 & 54 & 145 & 54 & 106 & 77 & 57 & 55 & 662 \\
\hline crazy_tiles_130356 & 15 & 58 & 57 & 146 & 59 & 103 & 80 & 61 & 54 & 633 \\
\hline crazy_tiles_5091369 & 64 & 58 & 16 & 162 & 55 & 16 & 82 & 55 & 53 & 561 \\
\hline dirty_floor_tiles_footprints_2564 & 95 & 62 & 59 & 156 & 59 & 106 & 79 & 61 & 60 & 737 \\
\hline dirty_tiles_200137 & 56 & 59 & 60 & 160 & 62 & 111 & 82 & 65 & 57 & 712 \\
\hline floor_tiles_030849 & 46 & 71 & 68 & 161 & 68 & 115 & 78 & 70 & 65 & 742 \\
\hline grubby_tiles_2565 & 58 & 66 & 65 & 165 & 67 & 112 & 88 & 76 & 72 & 769 \\
\hline kitchen_tiles_4270064 & 67 & 75 & 69 & 167 & 68 & 116 & 87 & 71 & 69 & 789 \\
\hline moroccan_tiles_030826 & 71 & 74 & 79 & 165 & 63 & 121 & 83 & 65 & 70 & 791 \\
\hline moroccan_tiles_030857 & 64 & 79 & 63 & 167 & 81 & 127 & 86 & 67 & 65 & 799 \\
\hline mosaic_tiles_8071010 & 71 & 70 & 72 & 173 & 68 & 122 & 91 & 72 & 71 & 810 \\
\hline mosaic_tiles_leaf_pattern_201005060 & 66 & 76 & 74 & 165 & 76 & 123 & 90 & 74 & 75 & 819 \\
\hline mosaic_tiles_roman_pattern_201005034 & 70 & 76 & 69 & 175 & 77 & 119 & 94 & 79 & 75 & 834 \\
\hline motif_tiles_6110065 & 74 & 73 & 74 & 173 & 81 & 127 & 92 & 74 & 67 & 835 \\
\hline ornate_tiles_030845 & 69 & 78 & 68 & 170 & 73 & 124 & 97 & 85 & 78 & 842 \\
\hline repeating_tiles_130359 & 80 & 74 & 64 & 184 & 81 & 115 & 107 & 91 & 63 & 859 \\
\hline
\end{tabular}

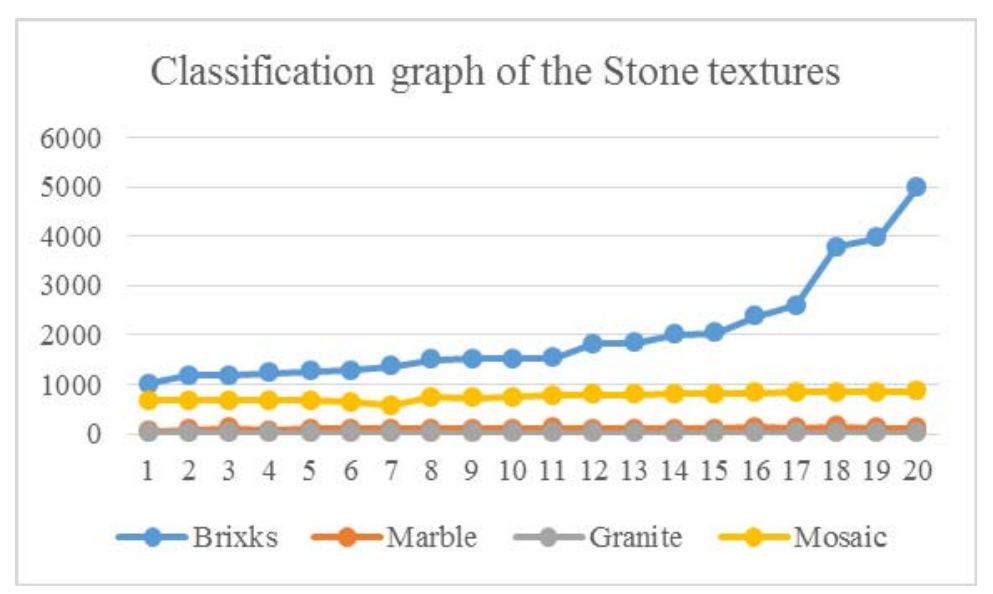

Figure 5. The proposed method generated classification graph 


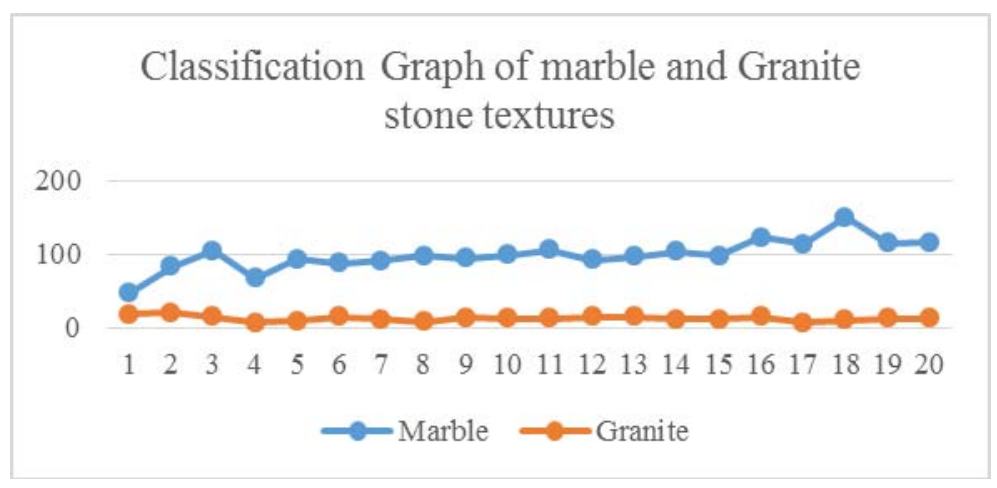

Figure 6. Generated Classification Graph of marble and Granite stone textures

The generated graph shown in figure 5 doesn't clearly indicate the granite and marble because of the occurrences of 5-bit T-patterns are less compare to other two groups. So, separate graph is generated for the occurrences of 5-bit T-patterns in marble and granite stone image. The generated classification graph for marble and granite is shown in figure 6. From the tables 1 to 4 and the classification graphs of Figure 5 and 6 assign an exact and specific classification of color stone images using rate of recurrences of overlapped 5-bit T-patterns. A new algorithm is derived for classification among these four classes i.e. Granite, Marble, Mosaic, and Brick group of stone textures based on the above table values and generated graph. The rate of occurrences of 5-bit T-patterns is dependent on the dimension of the texture that means when dimensions of the image changed; the rate of occurrences is also changed. To avoid such problems the present paper derived a classification algorithm independent of the image size. This algorithm categorizes the stone textures in to four groups irrespective of their dimensions. The derived algorithm uses $256 \times 256$ dimension as a bench mark. If the rate of occurrences of the test image cataract within the range of minimum to maximum quantity of occurrences of two and four transitions of a fastidious stone then test image is categorized as a particular group.

Algorithm 1: Stone texture classification based on Overlapped 5-bit T-Patterns

Let Sum of occurrences of Overlapped 5-bit T-Patterns SOTP

START

if $\operatorname{SOTP}<=\left(\frac{\sin }{\operatorname{arswas}} \times 20\right)$ then

Test image texture group is categorized as GRANITE class

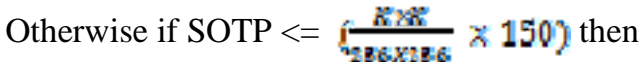

Test image texture group is categorized as MARBLE class

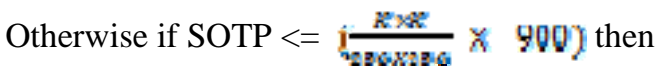

Test image texture group is categorized as MOSAIC class

Otherwise if SOTP $<=\left(\frac{\pi \times 2}{23 \times 236} \times 5000\right)$ then Otherwise

Test image texture group is categorized as BRICK class

Test image texture group is categorized as UNKNOWN class

STOP

\section{COMPARISON BETWEEN PROPOSED METHOD AND OTHER EXISTING METHODS}

The proposed method is compared with Wavelet based Histogram on Texton Patterns (WHTP) [18], which is used to classify the stone texture images into four categories by using wavelet based texton pattern histogram and texton feature evolution method [22], which is used to classify the images into four groups 
based on rate of occurrences of texton patterns. The proposed method is also compared with other existing method like Syntactic Pattern on 3D method [23] in which stone textures are classified into four categories based on the occurrence of systematic patterns. It is clearly obvious that, the proposed method show signs of a high classification rate than the existing methods. The percentage mean classification rate for the proposed method and other existing methods are represented in Table 5. The graphical representation of the percentage mean classification rate for the proposed method and other existing methods are shown in Figure 7. The Table 5 and Figure 7 shows the mean percentage classification of original images Google and scanned image. The mean percentage classification of proposed method and other existing methods of various databases are represented in Table 6 and graphical representation is shown in Figure 8.

Table 5. Mean percentage classification results of the proposed method and other existing methods

\begin{tabular}{ccccc}
\hline Image Dataset & $\begin{array}{c}\text { Syntactic Pattern on 3D } \\
\text { method }\end{array}$ & $\begin{array}{c}\text { Wavelet based Histogram } \\
\text { on Texton Patterns }\end{array}$ & $\begin{array}{c}\text { Texton Feature } \\
\text { Detection }\end{array}$ & $\begin{array}{c}\text { Proposed } \\
\text { Method }\end{array}$ \\
\hline Original & 93.29 & 93.15 & 95.56 & 96.85 \\
Google & 92.53 & 92.87 & 94.15 & 96.35 \\
Scanned & 93.3 & 93.82 & 95.27 & 96.29 \\
Average & 93.59 & 93.28 & 94.97 & 96.19 \\
\hline
\end{tabular}

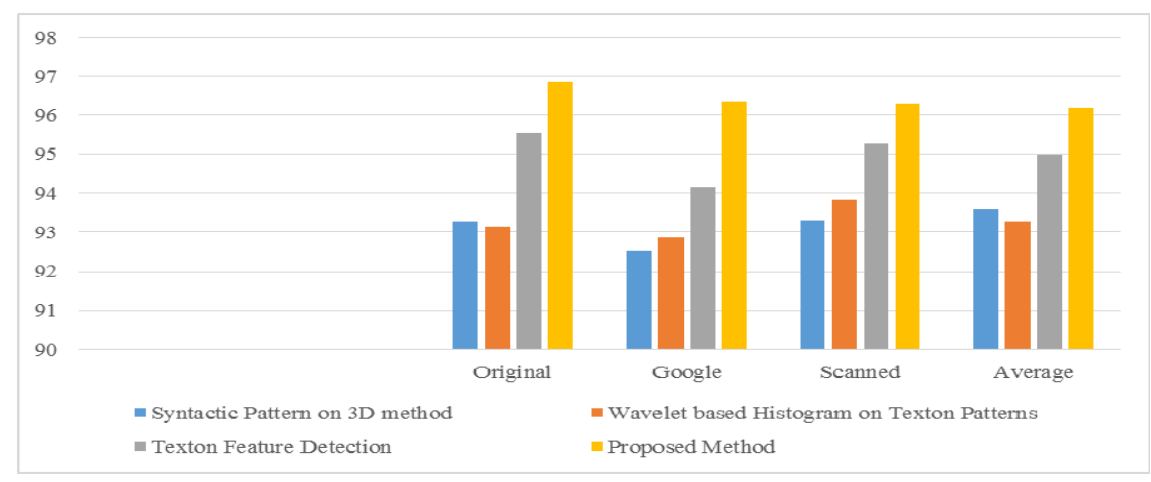

Figure 7. Classification chart of proposed method with other existing methods

Table 6. Mean percentage classification rates of the proposed method and other existing methods

\begin{tabular}{lcccc}
\hline \multicolumn{1}{c}{ Image Dataset } & $\begin{array}{c}\text { Syntactic Pattern on } \\
\text { 3D method }\end{array}$ & $\begin{array}{c}\text { Wavelet based Histogram } \\
\text { on Texton Patterns }\end{array}$ & $\begin{array}{c}\text { Texton Feature } \\
\text { Detection }\end{array}$ & $\begin{array}{c}\text { Proposed } \\
\text { Method }\end{array}$ \\
\hline VisTex & 93.15 & 92.87 & 95.46 & 95.95 \\
Texture Images Taken by & 92.87 & 91.7 & 95.12 & 96.35 \\
Camera & 93.32 & 93.56 & 94.86 & 96.76 \\
CuReT & 92.83 & 92.95 & 94.39 & 95.85 \\
Mayang & 93.05 & 93.05 & 95.23 & 95.93 \\
Paul Bourke & & & & \\
\hline
\end{tabular}

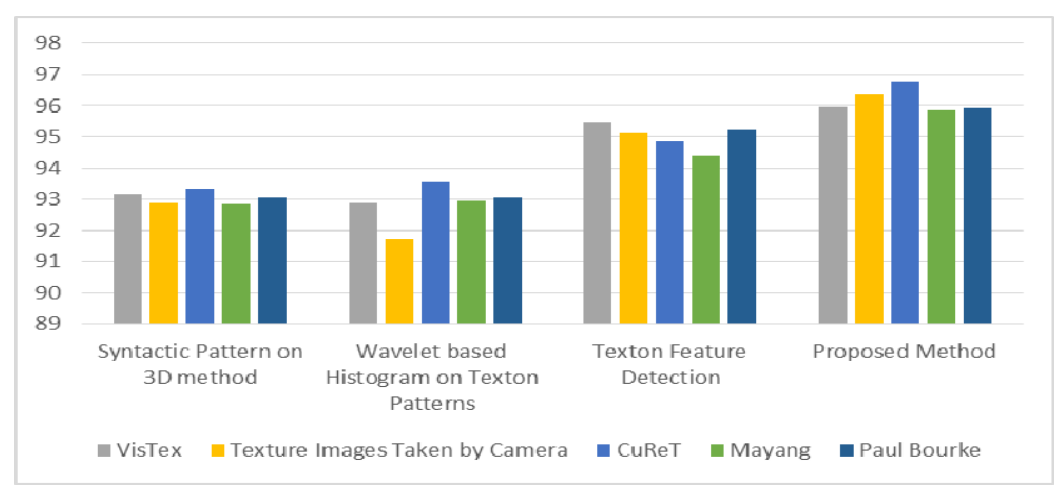

Figure 8. Mean percentage classification chart of the proposed method and other existing methods 
No standard classification algorithm is used to test the data base. The novelty of the proposed method is that the proposed technique is applied on huge dataset. Even though it is applied on huge dataset it gives good results when compare with the other existing methods. Still, no such technique is available to apply on large dataset.

\section{CONCLUSION}

The present paper derived a new approach called Overlapped 5-bit T-Patterns (O5TP) for stone texture classification. The present paper considered Nine 5 -bit T-patterns on each $5 \times 5$ sub image without losing the information about the image for texture analysis of the grey level image.The novelty of the proposed method is no standard classification algorithm is used for classification of stone textures. Proposed method is tested by using large set data base and got high \% of group classification i.e. the strength of the proposed method. When compare with the other existing method gives more accurate and precise classification results. The O5TP is computationally inexpensive. The experimental results clearly indicate the efficacy of the proposed O5TP over the various existing methods.

\section{REFERENCES}

[1] C. H. Chen, et al., "Handbook of Pattern Recognition and Computer Vision,” 2nd ed. Singapore, World Scientific, 2000.

[2] R. M. Haralick, et al., “Textural features for image classification,” IEEE Trans. Syst., Man, Cybern., vol/issue: 3(6), pp. 610-621, 1973.

[3] F. S. Cohen, et al., "Automated inspection of textile fabrics using textural models," IEEE Trans. Pattern Anal. Mach. Intell., vol/issue: 13(8), pp. 803-808, 1991.

[4] R. N. Sutton and E. L. Hall, “Texture measures for automatics classification of pulmonary disease,” IEEE Trans. Comput., vol/issue: C-21(7), pp. 667-676, 1972.

[5] H. Harms, et al., "Combined local color and texture analysis of stained cells," Comput. Vis. Graph., Image Process., vol/issue: 33(3), pp. 364-376, 1986.

[6] N. Hamdi, et al., "A new approach Based on Quantum Clustering and Wavelet Transform for breast cancer Classification: Comparative study,” International Journal of Electrical and Computer Engineering (IJECE), vol/issue: 5(5), pp. 1027-1034, 2015.

[7] T. Chang and C. C. J. Kuo, "Texture analysis and classification with tree-structured wavelet transform," IEEE Trans. Image Processing, vol/issue: 2(4), pp. 429-442, 1993.

[8] J. L. Chen and Kundu, "Unsupervised texture segmentation using multi-channel decomposition and hidden Markov models,” IEEE Trans. Image. Processing, vol/issue: 4(5), pp. 603-620, 1995.

[9] R. W. Conners, “Toward a set of statistical features which measure visually perceivable qualities of texture,” in Proc. Pattern Recognition Image Processing Conf., pp. 382-390, 1979.

[10] B. E. Reddy, et al., "Texture Classification by simple patterns on edge direction movements," IJCSNS, vol/issue: 7(11), pp. 220-225, 2007.

[11] V. V. Krishna, et al., "Classification of textures based on distance function of linear patterns using mathematical morphology,” Proceedings of ICEM, conducted by JNT University, India, 2005.

[12] V. V. Kumar, et al., "An Innovative Technique of Texture Classification and Comparison Based on Long Linear Patterns,” Journal of Computer Science, vol/issue: 3(8), pp. 633-638, 2007.

[13] V. V. Kumar, et al., "A measure of patterns trends on various types of preprocessed images," IJCSNS, vol/issue: 7(8), pp. 253-257, 2007.

[14] A. Suresh, et al., "An Innovative Technique of Marble Texture Description Based on Grain Components," International Journal of Computer Science and Network Security, vol/issue: 8(2), pp. 122-126, 2008.

[15] V. V. Kumar, et al., "Classification of Textures by Avoiding Complex Patterns, Science publications," Journal of Computer Science, 2008.

[16] U. S. N. Raju, et al., "Texture Description using Different Wavelet Transforms Based on Statistical Parameters," proceedings of the 2nd WSEAS International Symposium on WAVELETS THEORY \& APPLICATIONS in Applied Mathematics, Signal Processing \& Modern Science (WAV '08), Istanbul, Turkey, pp. 174-178, 2008.

[17] V. V. Kumar, et al., "A New Method of Texture Classification using various Wavelet Transforms based on Primitive Patterns,” ICGST International Journal on Graphics, Vision and Image Processing, GVIP, vol/issue: 8(2), pp. 21-27, 2008.

[18] J. S. Kiran, et al., "Wavelet based Histogram method for classification of textures,” IJECT, vol/issue: 4(3), pp. 149164, 2013.

[19] U. R. Babu , et al., "Texture Classification based on Texton Patterns using on various Grey to Grey level Preprocessing Methods,” International Journal of Signal Processing, Image Processing and Pattern Recognition, vol/issue: 6(4), 2013.

[20] L. Sumalatha and B. Sujatha, "A New Approach for Recognition of Mosaic Textures by LBP Based On RGB Model,” Signal \& Image Processing: An International Journal (SIPIJ), vol/issue: 4(1), 2013.

[21] B. Sujatha, et al., "Texture Classification Using Texton Co-Occurrence Matrix Derived From Texture Orientation,” International Journal of Soft Computing and Engineering (IJSCE) ISSN: 2231-2307, vol/issue: 2(6), 2013.

Stone Image Classification Based on Overlapped 5 bit T Patterns Occurrence on .... (Palnati Vijay Kumar) 
[22] U. R. Babu, et al., "Texture Classification Based on Texton Features," I.J. Image, Graphics and Signal Processing, vol/issue: 4(8), pp. 36-42.

[23] Suresh A. and V. V. Kumar, "Pattern Based Classification of Stone Textures on a Cubical Mask,” International Journal of Universal Computer Sciences, vol/issue” 1(1), pp. 4-9, 2010.

\section{BIOGRAPHIES OF AUTHORS}

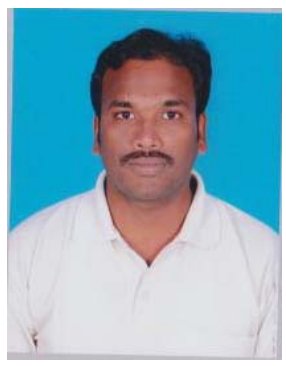

Palnati Vijay Kumar received his B.Tech (Computer Science \& Engineering) from SRKR Engineering College. He is pursuing his M.Tech (CSE) from Aditya College of Engineering, Surampalem, affiliated to JNT University Kakinada, Kakinada. His research interests include image processing, cloud computing.

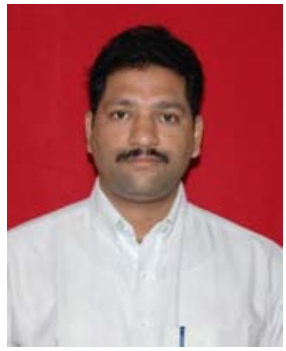

Pullela S V V S R Kumar is working as Professor of CSE at Aditya College of Engineering, Surampalem. He received his Doctorate from Acahrya Nagarjuna University, Andhra Pradesh. $\mathrm{He}$ is having more than 16 years of experience and published 12 research papers in various International Journals and Conferences. His research interests include Data Mining, Pattern Recognition and Image Processing. $\mathrm{He}$ acted as a reviewer to various International Conferences.

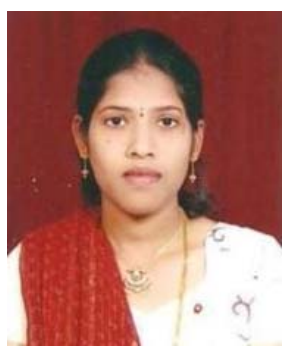

Nakkella Madhuri is working as Assistant Professor of CSE at Aditya College of Engineering, Surampalem.. She received her M.Tech (Computer Science \& Engineering) from JNTU Kakinada, Kakinada. Her research interests include image processing and cloud computing.

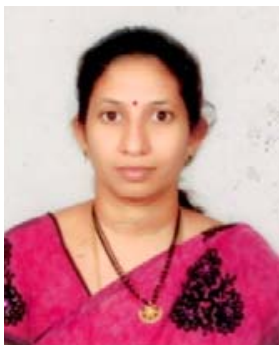

M. Uma Devi is working as Associate Professor of CSE at Aditya College of Engineering, Surampalem.. She received her M.Tech (Computer Science \& Engineering) from JNTU Kakinada, Kakinada and pursuing her Ph.D. from Acharya Nagarjuna University, Guntur, Andhra Pradesh. Her research interests include image processing and cloud computing. 